\title{
Making a Massive Open Online Course (MOOC) about Astrobiology: Why? For Whom? How?
}

\author{
Charles H. Lineweaver ${ }^{1, *}$ \\ ${ }^{1}$ Research School of Astronomy and Astrophysics and the Research School of Earth \\ Sciences, Australian National University, Canberra, ACT 0200, Australia
}

\begin{abstract}
Massive Open Online Courses (MOOCs) are becoming the textbooks of the $21^{\text {st }}$ century. I describe what a MOOC is, and try to answer the questions: Why make a MOOC? Who are MOOCs for? and How to make a MOOC? Anxiety about MOOCs replacing teachers is largely misplaced. I describe my on-going experience of putting together an astrobiology MOOC for the Australian National University.
\end{abstract}

\section{What is a MOOC?}

\subsection{History: from tutoring, to lecturing, to MOOCing}

Socrates, Plato and Aristotle participated in private tutoring and small group discussions (Fig. 1). They did not give lectures to hundreds of students. Lectures seem to have been invented by the first European universities in the $13^{\text {th }}$ or $14^{\text {th }}$ centuries (Fig. 2). N.B. this was before the 1440 invention of the printing press by Gutenberg.

At our meeting, the International Symposium on Education in Astronomy and Astrobiology, Karen Meech recounted some of her experiences organizing workshops, schools and fieldtrips. The most rewarding permanent learning and bonding was done with "long small meaningful discussions" in the context of a community of learners in some kind of isolation from the world. She seemed agnostic about the type of isolation: Hawaiian military barracks, island monasteries, ivory towers, Walden ponds, even deserts would do. At our conference, many of us found isolated conversations profitable, in the halls outside the lecture theatre, during coffee breaks or over dinner. Apparently, the ancients knew what they were doing.

\footnotetext{
* Corresponding author: charley.lineweaver@anu.edu.au
} 


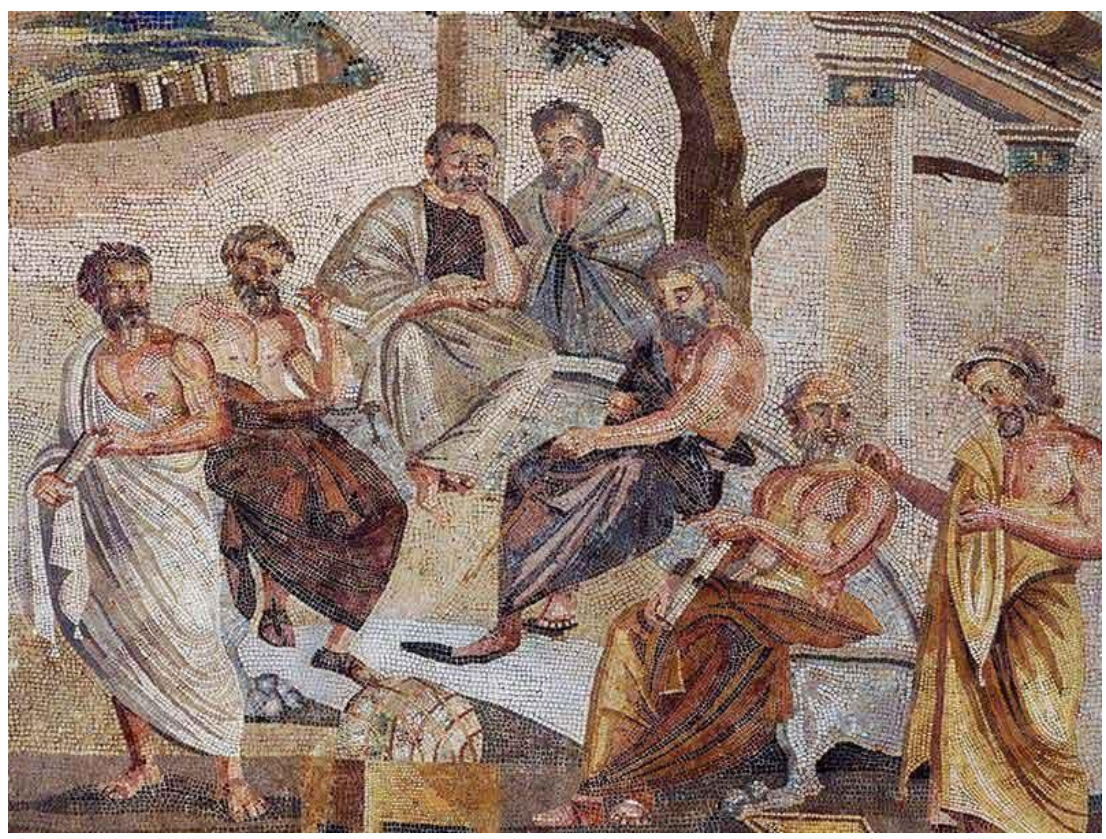

Figure 1 Socrates with a group of students. Small group discussions and personal tutoring were the main methods for teaching and learning. The small group tutoring sessions of modern universities and the intimate conversations over lunch at the margins of professional conferences, resemble these tried-and-true ancient pedagogical methods.

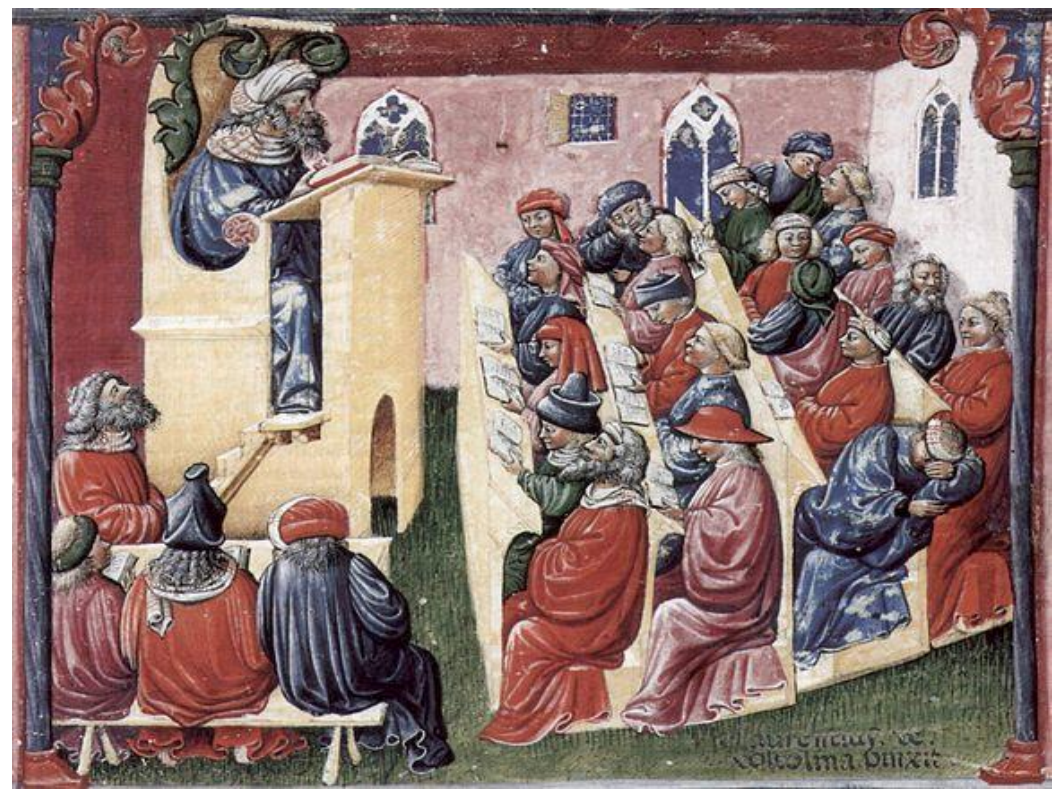

Figure 2 A professor lecturing to a couple of dozen students at the University of Bologna in the mid$14^{\text {th }}$ century. Many students aren't paying attention. Three are sleeping. Four are talking to each other. Three are spacing out. From medieval to modern university, disengaged boredom has always been a chronic disease of large lectures [1]. 
At universities all over the world, students languish in large required courses. Bored by what is going on at the front of the classroom, many students chat online or surf the web, put clothes on electronic dolls or just doze off - producing scenes similar to Fig. 2 from six hundred years ago. How can the lecture be improved? [2]

The quality of an education depends on the quality of the materials and the modes of instruction and learning: inspiring lectures, audio-visual aids, demonstrations, books with deep ideas, engaging activities and long, small, meaningful discussions with intimates that probe your deepest beliefs. At our meeting, Nataliya Kovalenko pointed out that there are many different types of intelligence [3]. It follows that there are correspondingly, many different ways to learn. Ken Robinson pointed this out with wit, charm and insight in the most popular TED talk of all time (www.ted.com/talks/ken_robinson_says_schools_kill_creativity\#t-2672).

Lectures have been the dominant form of instruction for many centuries and have had problems for a long time. When university education began to reach a significant fraction of the population in mid 1800s and early 1900s, financial constraints produced even larger lectures than at the University of Bologna. Recognizing the poor outcomes from boring lectures and the importance of active learning in small groups, "flipped courses" were conceived. My home university, Australian National University (ANU) is getting rid of many big lecture theatres on campus in anticipation of flipping most courses. They're called "flipped" because in normal university courses, lectures are given at school and homework is done at home. Flipped courses are the reverse: homework is done at school and lectures are watched at home.

The idea is that flipped classrooms give the students more access to the most valuable resource of a university: its energetic, insightful and inspirational teachers. Teachers' efforts are then shifted from one-size-fits-all lectures to small group-learning activities, tutorials, face-to-face teaching and occasional "long, small, meaningful discussions".

If lectures are to be watched at home, they have to be made and put online in some kind of digestible digital format. When these lectures are made available online for everyone, a flipped class is halfway to being a MOOC.

\subsection{Online education, Google, Wikipedia, YouTube videos}

Wikpedia has replaced encyclopedias. Online dictionaries are replacing printed dictionaries. Maps, newspapers, magazines, medical records, lawyers' briefs, pre-prints, professional journals, books - all of these printed materials are finding their most popular incarnations online. How-to manuals are being replaced by YouTube videos and video tours of entire museums are being put online. Everything is being put online. And convenient access to it all is provided by Google and other search engines.

Consider the Khan Academy as an example of online learning (www.ted.com/talks/salman_khan_let_s_use_video_to_reinvent_education/transcrip). When you log onto the Khan Academy (www.khanacademy.org), you'll see their motto:

You can learn anything.

For free. For everyone. Forever. 
It is for free. But you certainly can't learn everything, and it's certainly not for everyone. It's primarily an online resource for K-12 students. Salman Khan is an excellent tutor and has mastered the art of a clear informal discussion while writing on a tablet. See for example his explanation of what a mole

(www.khanacademy.org/science/chemistry/atomic-structure-and-properties/introduction-tothe-atom/v/the-mole-and-avogadro-s-number) is for young chemists or what the Krebs cycle (www.khanacademy.org/science/biology/cellular-respiration-andfermentation/pyruvate-oxidation-and-the-citric-acid-cycle/v/krebs-citric-acid-cycle) is for budding biochemists. An important niche for the Khan Academy seems to be helping high school students understand wikipedia entries. One important advantage of the Khan Academy seems to be its ability to inform teachers about the progress, strengths and weaknesses of their students -- particularly in math or other easily-assessed subjects -subjects in which "mastery" is most easily-defined, and there is an accepted order in which material is taught.

The subtitles of Khan Academy videos are in dozens of languages. The Khan Academy is a great new innovative online resource, but it has some teething problems (blogs.edweek.org/edweek/edtechresearcher/2012/06/dont_use_khan_academy_without_w atching_mmt2k_first.html) and it's not about to replace primary or secondary school teachers (ww2.kqed.org/mindshift/2014/05/06/how-are-teachers-and-students-using-khanacademy/).

Big History (school.bighistoryproject.com/bhplives) is another laudable effort towards online K-12 education. Online teaching resources to help K-12 teachers teach astronomy and astrobiology can be found

here (http://depts.washington.edu/astrobio/drupal/content/teachers),

here (http://www.astrobiologyacademy.org/),

here (http://astrobiology.asu.edu/Astrobiology/Education_Outreach.html), and

here (nai.nasa.gov/education-and-outreach/) [4,5].

However, MOOCs have little to do with K-12 education.

\subsection{MOOCs: the textbooks of the $21^{\text {st }}$ century (en.wikipedia.org/wiki/Massive_open_online_course)}

TED talks (www.ted.com/talks) and science videos like Veritasium (www.youtube.com/user/1veritasium), are wonderful resources for casual adult learners with undisciplined curiosities and desultory web-surfing habits. In contrast, MOOCs are organized and are trying to herd and tame these wild learners. MOOCs are supposed to be online versions of university courses. MOOCs may be the most important part of the new textbooks of the $21^{\text {st }}$ century. The quality is still low but is rapidly improving.

An initial commercial effort to replace university lectures were the recorded lectures of The Great Courses (www.thegreatcourses.com/courses/). These were expensive DVDs or CDs that were not online, but were sent to paying customers through snail mail. These courses were definitely not open and definitely not massive -- presumably because of their pricing. For example, Alex Filippenko's “Understanding the Universe: An Introduction to Astronomy" cost $\sim \$ 700$.

Since modern students are almost permanently distracted by social media, and are increasingly intolerant of attending lectures at a fixed time, they have demanded that universities record all lectures. For the past 10 years or so, teachers have been recording their lectures. Recording lectures and putting them online is one way to make lectures 
available. But students don't seem to take much advantage of them. Students don't like watching them. Maybe they're not interactive enough? Maybe the quality of the recording is not high enough? The recordings are made at various levels of 'automatic'. Often, only the powerpoint slides are recorded. There is no video of the lecturer gesticulating. The audio quality is often bad. When students ask questions in the live lectures, their voices are barely audible in the recording (you can't put lapel mics on all the students). And sometimes a lectern mic glues the lecturer to the podium.

It's very easy for students to press the pause button on a recorded lecture. Online, lecturers no longer have a captive audience. Maybe these recorded lectures are visually boring? For example, try attending a lecture without moving your head or even your eyes. Keep your eyes fixed on the slide. Boring.

When you attend a lecture in person, you look around at the people in the audience, at the speaker, at the slides being presented, back to the speaker who is pointing to a detail on the slide. Your field of view zooms in on that detail, then onto the face of the speaker. Then you hear an audience member muttering sceptically. You look at her. Then you see the other members of the audience snickering. Then you look back at the slide to try to understand why only your friend Joe, the evolutionary biologist, is laughing.

Even to imperfectly simulate this active experience for mass distribution requires many video cameras, many camera operators, special mics and lighting and good post-production. Such high production value costs lots of money. See for example Harvard's Justice course given by Michael Sandel (www.edx.org/course/justice-harvardx-er22-1x-2). Its close-tomillion-dollar price tag is much more than most universities are willing to invest in their MOOCs. With exceptional eloquence Sandel delivered his usual course with little modification. He didn't have to learn how to film, record sound, edit video and sync sound tracks. Here is what Sandel had to say about most MOOCs: "Watching a video that looks as if it were made with a convenience store security camera, as most Internet courses do, without the slides, syllabus and other materials available to actual students, dilutes the experience"

(http://www.nytimes.com/2009/09/26/arts/television/26sandel.html?pagewanted=all\&mcub $\mathrm{z}=3$ ). This may be true, but Michael, is it just? For a cheaper ( $1 / 2$ the price ?) version of a MOOC made with only three cameras and three camera operators see Eric Lander's edX biology course (www.edx.org/course/introduction-biology-secret-life-mitx-7-00x-7).

MOOC content is usually not such a close by-product of a traditional lecture as the two examples above. Most MOOCs consist of a series of short and to-the-point videos usually between 5 and 10 minutes long, created explicitly for an online audience. The videos are interspersed with 'knowledge checks'. These are easy, usually multiple choice questions meant to consolidate the content of the video. See for example Paul Francis' and Brian Schmidt's ANU edX course Astrophysics: Exploring Exoplanets (www.edx.org/course/astrophysics-exploring-exoplanets-anux-anu-astro2x-1) [6].

\section{Why make a MOOC?}

\subsection{Selfish Curiosity}

In her talk at the Utrecht Conference, Nataliya Kovalenko's showed a slide that said something like: "We remember $5 \%$ of what we read, $10 \%$ of what we hear, $50 \%$ of what we 
do, and $95 \%$ of what we teach." "Aha", I said to myself, "Maybe that's why I'm making an astrobiology MOOC. I want to learn more about astrobiology. To learn most effectively, I should teach it." I must conclude that selfish curiosity is a dominant motivation for me making a MOOC.

As I write the words that will be recorded in the MOOC, I have to think more carefully and more clearly. Compared to live lectures, MOOC videos seem to have a much lower tolerance for hemming and hawing and digressions. They need to be tightly scripted, but audiences are unforgiving if you then stone-facedly read the script to the camera. Boring next tab.

\subsection{Equality of educational opportunity}

Traditional high quality university education is expensive. You are surrounded by a community of learners paying for the privilege to be with each other. Very few young people in the world have had the educational opportunities that I have had (and that most of the participants at this conference have had). Such privileged opportunities are probably available to 5 or $10 \%$ of the world, predominantly in rich countries. For the sake of equality, to level the playing field, to give everyone a fair go, to avoid World War III -whatever parts of this educational privilege that can be put online and more equitably distributed, should be. Probably the best thing about MOOCs is that they are free. Anyone with an internet connection can take MOOC courses (caveat: internet connections are not yet free).

\subsection{Support from home university}

MOOCs are often made by an academic with no experience in TV or making videos, who has been encouraged by his or her home university. ANU has joined the edX (www.edx.org) effort spear-headed by Anant Agarwal (people.csail.mit.edu/agarwal/) at MIT. Charles Cockell's University of Edinburgh course Astrobiology and the Search for Extraterrestrial Life (www.coursera.org/learn/astrobiology) is on the Coursera platform. Udacity and FutureLearn are other platforms. Read about the differences here (en.wikipedia.org/wiki/EdX).

Each year for the past few years ANU has put out a call to academics: propose a MOOC and if we like it and we think you're a good teacher, we will support you in making it. "Support" can come in many forms. The most valuable form of support is an experienced production team of video editors whose media skills complement the content-organizing skills of an academic. Sometimes "support' is predominantly financial, and this has been my experience at ANU.

Without lots of video-editing assistance, making a MOOC can be as time consuming as writing a textbook. To make MOOCs, universities invest different amounts -- some invest a few thousand dollars, others invest hundreds of thousands of dollars. Like Hollywood movies, the quality of the results don't always scale with production costs.

\section{For Whom?}

MOOCs are for everyone who...

1) has an internet connection 
2) has time to learn

3) has motivation to learn

This last group is sometimes called "free-choice learners" [7]. These can be retirees, university students with free time, ambitious high school students or busy people who don't have time to go to university. Online education is like the ocean; you get a surfboard and try to find some good waves. Online education is like a toll-free highway: you get a car and go where you want. Some go to where you can make lots of money. Others go for enlightenment. Some seek peace in the country while others seek excitement in the city. I suppose someday soon, students could be forced to take a MOOC but I haven't heard of that yet.

The "M" in MOOCs means massive. That can mean anywhere from 100 to 100,000 students will enroll. There is no limit. MOOCs can have an enrolment three orders of magnitude larger than the largest university course [8]. But high dropout rates are an ongoing problem for MOOCs. But 'dropout rate' is probably a misnomer. Most people who enroll are still just window shopping. I believe this because I have signed up for about 10 MOOCs and have followed one religiously, one pretty regularly and a few randomly. The rest are just casual acquaintances I don't think about very often.

\section{How to make a MOOC?}

When you create a MOOC for the edX platform, you need to decide: are you going to run it "instructor-paced" or "user-paced". Instructor-paced means every week new material that you have previously prepared, is made available. With more students working simultaneously on the same material, real-time feedback is easier and student discussion forums are more active. There is also a start and end date. In contrast, user-paced (or archived) MOOCs can be taken at any time. There is no start or end time. You can enroll and listen to any of the videos. You can skim the quizzes and assignments. It's like perusing a book in a book store. That is the way I usually identify good MOOCs for later consumption.

\subsection{Equipment}

To record video I am using a Panasonic Lumix GH4 video camera with a 15-35 mm lens. Accessories include two extra battery packs, a few $64 \mathrm{~Gb}$ SD cards $(280 \mathrm{MB} / \mathrm{s}$ SCXC II, U3), a JOBY Gorilla tripod and a camera case. To record audio I am using a Zoom H6 Handy recorder, and RHODElink wireless transmitter (with lapel mic) and receiver. I also have two more lapel mics, a 32 GB SD card for sound and a dozen high quality, rechargeable AA batteries. All of this cost about $\$ 8000$ and could fit inside a medium sized leather satchel. The JOBY tripod was good for many situations, but I found that I kept needing to find a big book or a trash can to put it on, to raise the camera to the level of eyeballs of interviewees sitting at a table. Interestingly, having the camera at eyeball height seems to be more important than anything the interviewee says. So, after a year I bought a larger tripod (Giottos MH5400), which I have found useful for interviews but also, importantly, it is long enough to raise the camera to my eyeball level when I'm standing and talking to the camera. Alas, I can't fit this tripod into my satchel : (

I was advised to use Camtasia for video editing because of its ease of use. But one of my tech-savvy PhD students convinced me to use Adobe Premiere. Learning Premiere has been a steep learning curve, but I have been assured that it will have been worth it. I also had to 
up my game when it came to making powerpoint slides which double as a way to storyboard scenes. Colors and fonts and backgrounds became much more important.

To animate a powerpoint slide you have to turn it into a series of images. Start with perfecting the final slide. Put all the labels and arrows and shading you want to appear onto the slide. Make sure they all fit and don't clash. This will be the final slide of your sequence. Then duplicate the slide and remove the last item you want to come up. Put this new slide before the last one. Repeat this procedure until all the labels and arrows and shading are gone. This bare image is the first in the series. Then when you click through the series of slides, the labels and arrows won't shift around and in the last slide all the items will appear where you want them. This produces an animated series of powerpoint slides. This procedure can be summarized as "start at the end". Beginners like myself try to do the first slide first, then the second, then the third. Then the slide starts to get crowded, so you have to adjust things, but this adjustment messes up the positions of the earlier arrows and labels. These labels and arrows and shading are necessary because you can't video a laser pointer and if you're not standing in front of the slide, you can't point with your hands.

I learned another curious fact while making a MOOC. Audio quality is of prime importance. Audio, not video, is used to hold a video together. For example, when the audio is of a person speaking, the video can be of that person or of ANY other image EXCEPT video of another person speaking.

Does length matter? It does for video. There seem to be some very good reasons to limit the duration of MOOC videos to 5-10 minutes (wistia.com/blog/does-length-matter-it-doesfor-video) [9].

\section{Don't worry, MOOCs may displace you, but they won't replace you.}

"...the report of my death was an exaggeration." Mark Twain

Similarly, the imminent demise of the lecture at universities due to the advent of MOOCs, has been grossly exaggerated.

At university, I learned the most from listening to the lectures of inspiring and passionate professors. I learned from reading books and from small group discussions -- and by trying to put thoughts to paper, and then seeing my scribblings become more concise and coherent by the removal of half of what I had written by an encouraging prof with a clever red pen. I learned by preparing in small groups for tests, and by arguing with teaching assistants and professors and by asking questions -- thousands and thousands of questions in an atmosphere that allowed (even encouraged) inquiry. Almost uniquely, universities did not stifle the kind of aggressive confrontational curiosity that seemed to be the only way I could deal with being domesticated and civilized. Some, but certainly not all of this can be canned and put online.

At research universities, researchers are known throughout the world for their research disseminated in international journals. If these researchers are also excellent teachers, their reputation is limited to their students and their universities. MOOCs are beginning to change this weird inequality. Teaching excellence is about to go global.

The advent of MOOCs has produced some anxiety: Universities around the world are trying to figure out what to do with the internet. If education is free and open to everyone with an 
internet connection, what's left for a university to do? If the future of university education is free and online, available anytime, anywhere, then universities start to ask themselves "Where is our money going to come from?"

Currently, the same courses are taught hundreds of times simultaneously across the world. Many are taught by academics and researchers whose skills lie elsewhere. This large degree of redundancy and mediocrity is due to the spatial separation of students. Not all students in the world go to the same university. If they did, only one lecture on each subject would be necessary. If thousands of MOOCs conceived and delivered by the best lecturers from thousands of different universities can service the entire world in all subjects -- and these online lectures can be translated into all languages, what is to become of the rest of us? For most of us academic types, lecturing is only a small part of what we do. If we have to switch from giving our own lectures, to explaining the contents of excellent, insightful and entertaining online lectures to small groups of students -- that doesn't sound like a catastrophe to me. Universities will still need a boat-load of teachers to run small group tutorials. This person-to-person format is too intimate (like sex) to be easily put online (at least during our generation).

Universities finance MOOCs because they want to promote themselves, their brand and their quality teaching on the world stage. So universities of the 21 st century, if you have a video-genic lecturer, encourage them to make a MOOC about something they are passionate about. Put some money into filming and video editing and production value [10]. Put the resulting videos online. This will advertise to the world the pedagogical prowess of your academic, and concentrate expensive teaching time on "long, small, meaningful discussions" -- like Socrates.

\section{Discussion and Summary}

\subsection{Aggregation}

The convenience and ubiquity of the internet, and the high percentage of people online, have created fertile territory for university-level formal education. Currently, universities give credits for taking courses, but to get the final prize, a degree, you need to have a bunch of credits that add up to a major. If you want to major at a university, you have to take a bunch of related courses. You don't get a degree for taking a single course.

Universities now give certificates for the completion of individual MOOCs, but I think this is about to change. As MOOCs become more popular and substantial they become part of the degree-granting process. As MOOCs multiply, they are beginning to aggregate into coherent groups, much as individual university courses are aggregated into majors.

I think MOOCs will come of age when they can be aggregated into groups of 10 or 20 or 30 .

Pamela Gay (en.wikipedia.org/wiki/Pamela_L._Gay), one of the most knowledgeable online educators and promoters of an online astronomy podcast

(http://www.astronomycast.com/) sees the future of online education in citizen science and in online education less formal than MOOCs. She is helping to create an educated mob of citizen scientists. Compared to citizen science and her astronomy podcast with Fraser Cain, most MOOCs are highbrow and of lower production value. Academics do not know how to edit videos or create interesting special effects. Compared to citizen science and science 
documentaries, academics know more about the subject matter and content but less about lighting, camera angles and audio quality.

Academics know how to inform but not necessarily entertain. They are used to having captive audiences without pause buttons. Education and entertainment are not mutually exclusive. Unfortunately, many lecturers think they are and stubbornly resist being entertaining. Hence their videos are doomed to be boring. Optimally, MOOCs are interesting AND entertaining (like good lectures).

Pamela hopes MOOCs will die by fire. I think this means that she hopes they will languish in their own highbrow boredom, unwilling to adopt the new media-friendly necessities.

I disagree with Pamela. Fastfood does make a lot of money, and clickbait is fleetingly interesting ("Neutrinos are awesome!"), but I'm quickly getting tired of being manipulated by clickbait. Curiosity driven research will produce enough curiosity-driven video-genic academics to make the substantial and insightful MOOCs that the best education needs. This may limit MOOCs' popularity, but popularity and number of clicks is not the only, or even the most important measure of the success of universities. It is also to make scientific progress. Universities need to produce an educated populace [11] and as many Einstein's as possible. Very few will be enough.

I want to thank four women who made my participation at this International Symposium on Education in Astronomy and Astrobiology possible: Muriel Gargaud, Beatriz Garcia, Inge Loes ten Kate and my mother, Sally Howe. I also want to thank the Utrecht University for hosting such an educational meeting. I thank Chris Impey and Inga Loes ten Kate for allowing me to interview them for the MOOC I'm making.

\section{References}

1. E. Washor and C. Mojkowski, Student disengagement: It's deeper than you think. Kappan, May 2014

2. K.P. Cross, not can, but will college teaching be improved, New Directions for Higher Education, 17, Spring 1977

3. H. E. Gardner, Frames of Mind : The Theory of Multiple Intelligences 1983

4. E.E. Prather and T.F. Slater Education Paper: An Online Astrobiology Course for Teachers, Astrobiology, 2, 2 (2002)

5. J.M. Bailey, T.F. Slater, A review of astronomy education research. Astronomy Education Review, 2(2), 20 (2003).

6. P.J. Francis, Fantasy Universes: Inquiry Learning in Astrophysics On-Campus and Massive Open Online Courses. Int. J. of Innovation in Science and Mathematics Education, 23(6), 75-87 (2015)

7. E. Washor and C. Mojkowski Leaving to Learn: How Out-of-School Learning Increases Student Engagement and Reduces Dropout Rates, Heinemann, (2013)

8. P.J. Francis, Students Demographics and behaviour in a series of Australian Massive Open Online Courses (MOOCS), Proceedings of the Australian Conf. on Science and Mathematics Education (formerly UniServe Science Conf). ACSME Proceedings: Transforming practice: Inspiring innovation openjournals.library.sydney.edu.au/index.php/IISME/article/view/8832 (2015) 
9. P.J. Guo, J. Kim and R. Rubin How Video Production Affects Student Engagement: An Empirical Study of MOOC Videos, L@S 2014, March 4-5 http://dx.doi.org/10.1145/2556325.2566239

10. A. Cross, M. Bayyapunedi, E. Cutrell, A. Agarwal and W. Thies, TypeRighting : Combining the Benefits of Handwriting and Typeface in Online Educational Videos, CHI 2013, April 27-May 2, 2013, Paris, France

11. C. Kerr Education Tomorrow : For Whom? Why? Address presented to the Western Regional Assembly of the College Entrance Examination Board, San Diego, Calif. January 1976. 